\title{
Surgical treatment and outcomes of extraarticular proximal tibial nonunions
}

Michael J. Gardner · Jose B. Toro-Arbelaez •

Mathias Hansen - Sreevathsa Boraiah •

Dean G. Lorich · David L. Helfet

Published online: 8 October 2008

(C) Springer-Verlag 2008

\section{Erratum to:}

Arch Orthop Trauma Surg (2008) 128:833-839 DOI 10.1007/s00402-007-0383-y

The name of the third author, Mathias Hansen, was unfortunately omitted.

The complete authorship is given here.

Michael J. Gardner

Jose B. Toro-Arbelaez

Mathias Hansen

Sreevathsa Boraiah

Dean G. Lorich

David L. Helfet
Address:

Mathias Hansen

Clinic for Trauma, Hand and Reconstructive Surgery, City Hospital Worms, Gabriel-von-Seidl-Straße 81, 67550 Worms, Germany

We apologize for this omission.

The online version of the original article can be found under doi: 10.1007/s00402-007-0383-y.

M. J. Gardner $(\bowtie) \cdot$ J. B. Toro-Arbelaez · S. Boraiah .

D. G. Lorich · D. L. Helfet

Department of Orthopaedic Surgery,

Hospital for Special Surgery, 535 East 70th Street,

New York, NY 10021, USA

e-mail: gardnerm@hss.edu

\section{Hansen}

Clinic for Trauma, Hand and Reconstructive Surgery,

City Hospital Worms, Gabriel-von-Seidl-Straße 81,

67550 Worms, Germany 